ceeded to the University of Manchester. Work with Prof. A. R. Todd on a synthetic approach to the study of nucleosides involved the development of new methods for the synthesis of purines and their 9 -substituted derivatives and a general, unambiguous synthesis of 9-glycosidopurines. Application of these methods to the synthesis of 9-d-ribosidoadenine gave a product which differed only in the size of the sugar ring from the important naturally occurring nucleoside adenosine. He was awarded the degrees of M.Sc. (1942) and Ph.D. (1944) of the University of Manchester on the results of these investigations. After a period of work on penicillin chemistry under a grant from the Medical Research Council, he was awarded an I.C.I. fellowship and resumed work with Prof. Todd at Cambridge on the chemistry of the nucleotides, particularly those possessing coenzyme function. By the application of a new phosphorylating reagent, dibenzyl chlorophosphonate, muscle adenylic acid and adenosine diphosphate were synthesized from adenosine in good yield, thereby enabling these important biological substances to become more accessible for biochemical study and, at the same time, proving their structures beyond doubt. Since then, Dr. Baddiley has been engaged on a total synthesis of adenosine triphosphate and is at present spending a year at the Wenner Grens Institut, Stockholm, to extend his knowledge of nucleotides on the biological side and to acquire tracer technique for his future investigations. The Meldola Medal is the gift of the Society of Maccabæans and is normally awarded annually to the chemist who, being a British subject and less than thirty years of age, shows the most promise as indicated by his or her published chemical work.

\section{Royal Society of Edinburgh: Awards}

THe council of the Royal Society of Edinburgh has awarded the Keith Prize for the period 1945-47 to Dr. Charlotte Auerbach, of the Institute of Animal Genetics, University of Edinburgh, for her contributions to genetics published in the Society's Proceed. ings, during the period of the award and previously. The Neill Prize for the period 1945-47 has been awarded to Dr. Robert Broom, for his contributions to our knowledge of the fossil vertebrates of the Karroo Beds of South Africa. At the ordinary meeting of the Society held on May 3, David Anderson-Berry Prizes were presented to Dr. Ralston Paterson, director of the Holt Radium Institute, Manchester, for his book on radiotherapy; and to Dr. P. C. Koller, of the Royal Cancer Hospital, London, for his researches on the effect of radiation by $\mathrm{X}$-rays on experimental and pathological material.

\section{Royal Institute of Chemistry : Anniversary Meeting}

Fon the first time in the history of the Royal Institute of Chemistry, the annual general meeting was held this year outside London, the Birmingham and Midlands Section of the Institute having invited the Council to hold the anniversary meetings in Birmingham during April 15-17. An exhibition entitled "The Chemist in the Midlands", which was opened by the president of the Institute, Dr. G. Roche Lynch, on April 15 at the Central Technical College, afforded a remarkable demonstration of the present-day activities of chemists in research, industrial production and the public services in the Midlands, and of the organisation and development of scientific and technical education and research in the area. The exhibition was open to the public during the following two days and special arrangements were made for visits by parties of schoolchildren. Later the officers of the Institute received a civic welcome from the Deputy Mayor of Birming. ham (Alderman A. F. Bradbeer). The general proceedings of the meeting included a lecture by Prof. R. P. Linstead on "The Chemical Research Laboratory, Teddington', and a lecture by Prof. M. Stacey on "The New Fluorocarbon Chemistry". At the annual general meeting, two special resolutions, moved by the president, were passed : one authorizing the Council to submit to the Privy Council a petition for a new charter for the Institute; the other consenting to the raising, as from January 1, 1949, of the annual subscriptions of fellows and of associates. The following were elected officers for 1948-49: President: Dr. Gerald Roche Lynch; Vice-Presidents : Prof. H. V. A. Briscoe, Prof. F. Challenger, Mr. G. E. Dodds, Prof. Alexander Findlay, Mr. E. T. Osborne, Mr. A.J. Prince; Hon. Treasurer: Dr. D. W. Kent-Jones.

\section{American Awards to British Scientific Workers}

THE United States Military Attache in London, Major-General Clayton L. Bissell, presented United States awards and decorations to eighteen British citizens, one Canadian and one Australian, on April 29, for services during the Second World War. Among the awards were the following: Medal of Freedom with Silver Palm: Prof. S. Zuckerman, professor of anatomy, University of Birmingham, scientific adviser to the Deputy Commanding General of Allied Force Headquarters and to Supreme Headquarters Allied Expeditionary Force, from January 1943 until May 1945; Medal of Freedom: Prof. W. Norman Thomas, professor of engineering, University College, Cardiff, head of the $R E 2 / 4$ Division of the Research and Experiments Department, Ministry of Home Security; Bronze Star: Miss Peggy Furse, civilian personnel officer, Personnel Section, Psychological Warfare Division, Supreme Headquarters Allied Expeditionary Force (Rear Echelon), from March 1944 until July 1945.

\section{Royal Botanic Gardens, Kew : Recent Acquisitions}

Mr. W. R. SHERRIN has presented to the Herbarium of the Royal Botanic Gardens, Kew, his valuable collection of bog-mosses (Sphagnum). The material occupies two standard-sized cabinets, and the specimens, representing approximately 4,350 separate collectings, are mounted on 1,360 sheets. The specimens have been determined with the utmost care and largely formed the basis of Mr. Sherrin's "Illustrated Handbook of the British Sphagna", published by Taylor and Francis, London, in 1927. The Sphagna are of considerable interest to botanists for a number of reasons and they also have economic importance. The genus is a large one (Warnstorff, in 1911 , accepted 342 species, some with a considerable number of varieties and forms) and occurs all over the world; but the species thrive best in the damp, humid climates of the temperate zone in Europe, Asia and America. Typically, the species grow in bogs and other wet places where the water is more or less acid, often very highly acid. Their dead remains play an important part in the building up of the masses of peat filling such bogs. Newly dried Sphagnum has been used for packing material, for making coarser kinds of paper, in horticulture, and in the manufacture of molasses feeds for livestock. Taxonomically the genus is a difficult one. The 